\title{
CITRAAN DALAM PUISI DAERAH SULAWESI SELATAN
}

\author{
(IMAGERY IN SOUTH SULAWESI'S POEMS)
}

\author{
Murmahyati \\ Balai Bahasa Provinsi Sulawesi Selatan dan Provinsi Sulawesi Barat \\ Jalan Sultan Alauddin Km7, Tala Salapang, Makassar \\ Telepon (0411) 882401 faks. (0411) 882403 \\ Pos-email atimurmahyati@yahoo.com.
}

\begin{abstract}
This article aims to explain about imagery in South Sulawesi's poems. The result to expect is story concerning the imagery poetry of South Sulawesi. Method of research used is descriptive method with sociological literature approach. Data were collected by using library research method. The researcher has found visual imagery, auditory imagery, olfactory imagery, tasting imagery and motion imagery.
\end{abstract}

Keywords: imagery, South Sulawesi poems

\begin{abstract}
Abstrak
Artikel ini bertujuan memaparkan tentang citraan dalam puisi daerah Sulawesi Selatan. Hasil yang diharapkan adalah risalah yang menyangkut citraan puisi daerah Sulawesi Selatan. Metode yang digunakan adalah metode desktiptif dengan pendekatan sosiologi sastra. Teknik pengumpulan data dengan menggunakan studi pustaka. Pada penelitian ini, ditemukan citraan yang ditemukan, antara lain citraan penglihatan, citraan pendengaran, citraan penciuman, citraan pencicipan, dan citraan gerak.
\end{abstract}

Kata kunci: citra, puisi daerah Sulawesi Selatan

\section{Pendahuluan}

Pembangunan di bidang kebudayaan sebagai pembangunan nasional juga meliputi usaha pembinaan dan pengembangan sastra, karena karya sastra adalah manifestasi kehidupan bangsa di masa lampau, masa kini, dan masa yang akan datang.

Berbahagialah kita, bangsa Indonesia, karena memiliki beraneka ragam bahasa dan sastra daerah sebagai warisan nenek moyang kita yang tidak ternilai harganya. Sastra daerah yang beraneka ragam itu turut mewarnai khazanah sastra Indonesia dan me- rupakan alat penunjang untuk memperkaya kesastraan kita pada umumnya. Pengalaman-pengalaman jiwa yang dituangkan ke dalam sastra daerah itu dapat berfungsi sebagai alat yang tangguh untuk membendung arus masuknya kebudayaan asing yang tidak sesuai dengan kepribadian serta kepentingan bangsa Indonesia. Melalui sastra diperoleh nilai-nilai tata hidup sebagai sarana kebudayaan dan komunikasi antara generasi masa lampau, generasi sekarang, dan generasi yang akan datang. Melalui sastra kita dapat menghargai kehidupan. Dalam sastra daerah terdapat 
nilpai-nilai budaya untuk menunjang kehidupan nasional. Penghayatan terhadap karya sastra, dalam hal ini sastra daerah dan kemajuan teknologi modern merupakan dua hal yang harus saling mengisi untuk mencapai keseimbangan dan keselarasan dalam pembangunan nasional yang juga merupakan pembangunan lahir dan batin. Kedua hal ini belum tercapai. Oleh karena itu, penelitian karya sastra daerah perlu mendapat perhatian dan memerlukan penelitian sungguh-sungguh.

Kian tinggi apresiasi sastra seseorang, maka kian meningkat pula keterampilan bersastra mereka. Keterampilan bersastra, turut pula menunjang keterampilan berbahasa, keterampilan berpikir, keterampilan berkepribadian, dan keterampilan bermasyarakat (Howard, 2001: 45).

Menurut pengamatan penulis, sastra daerah masih banyak yang belum tergali, sedangkan yang sudah dituliskan dan pernah ada pun sudah mulai menghilang dari ingatan masyarakat daerah itu. Oleh karena itu, usaha-usaha yang terarah dan terencana untuk membina dan mengembangkan sastra daerah ini perlu dilaksanakan secara berkesinambungan.

Situasi kehidupan sastra daerah yang tergambar di atas merupakan tolok ukur bagi kita untuk mengatur tindakan selanjutnya, terutama dalam upaya meningkatkan daya apresiasi masyarakat terhadap sastra. Sepanjang masih bersifat tradisi lisan, sastra daerah akan tetap terbatas pada ruang dan waktu. Dalam hal ini, penulis mencoba membahas citraan dalam puisi-puisi daerah Sulawesi Selatan.

Rumusan permasalahan yang akan dibahas dalam penelitian iniadalah: 1) Bagaimana penggambaran citra baik bentuk maupun pengungkapan isinya dalam puisi-puisi daerah Sulawesi Selatan? dan 2) unsur-unsur citra apa saja yang mempengaruhi dan menghiasi puisi-puisi daerah Sulawesi Selatan.

Berdasarkan latar belakang perumusan masalah di atas, kegiatan ini bertujuan melakukan penelitian tentang citraan dalam puisi-puisi daerah Sulawesi Selatan, sehingga hasil penelitian itu dapat digunakan sebagai sarana pemupukan apresiasi masyarakat terhadap karya sastra serta dapat dijadikan sebagai sumber penelitian lebih lanjut. Hasil yang diharapkan adalah risalah penelitian yang menyangkut citra yang terdapat di dalam puisi daerah Sulawesi Selatan agar masyarakat umum dapat mengetahui bahwa di dalam puisi-puisi daerah itu terdapat nilai-nilai yang berguna bagi kehidupan berbangsa dan bernegara.

\section{Kerangka Teori}

Citra (image) itu gambaran yang dihasilkan kesan mental. Citraan (imagery) adalah bayangan visual yang hadir lantaran ada sesuatu yang menyentuh saklar memori untuk mengaitkannya pada sesuatu yang lain. Sebuah kata, simbol, atau benda tertentu yang merangsang memori membayangkan atau memvisualisasikan sesuatu atau peristiwa, termasuk kategori pencitraan. Saleh Saad (1967: 2) juga menuturkan dalam artikel sastra, ketika kata atau simbol itu mencitrakan sesuatu, memori seketika menghidupkannya sesuai dengan pengalaman masa lalu dan pengenalan pada sesuatu.

Pencitraan adalah gambaran angan yang bermanfaat dalam pemahaman puisi yang acuan maknanya bersifat indrawi. Citraan memungkinkan kita untuk mencitrakan atau membayangkan kata-kata. Citraan ini sangat bermanfaat dalam menghidupkan puisi.

Pencitraan (imaji) adalah pengungkapan perasaan sensoris penyair kedalam kata dan ungkapan sehingga terjelma gambaran suasana yang lebih konkret (Teeuw, 1983: 20--21). Menurut Stanton (1965: 78) pencitraan dibatasi oleh pengertian kata atau susunan kata yang dapat mengungkapkan pengalaman sensoris seperti penglihatan, pendengaran dan perasaan.

Sastrawan sering juga menggunakan imaji ( $\mathrm{ci}$ traan) untuk menambah kepuitisan sebuah puisi. Altenberd dalam Pradopo (2002: 79-80) mengatakan "citraan adalah gambar-gambar angan pikiran dan bahasa yang menggambarkannya, sedangkan setiap gambar pikiran disebut citra atau imaji (image)." Kata-kata yang dipergunakan penyair tidak sama artinya dengan kata-kata di dalam kamus. Seorang penyair tidak hanya bermaksud menyampaikan makna lugas. Lebih dari itu, penyair ingin membentuk citraan atau imaji tertentu dalam pikiran pembacanya. Makna yang ditimbulkan itu disebut makna citraan 
atau makna imaji. Dengan kata lain, citraan adalah cara membentuk citra mental pribadi (penyair) atau gambaran sesuatu.

Citraan (gambaran angan-angan) adalah gambaran-gambaran dalam pemikiran dan bahasa yang menggambarkannya. Gambaran pemikiran ini adalah sebuah efek dalam pemikiran yang sangat menyerupai gambaran yang dihasilkan oleh pengungkapan kita terhadap sebuah objek yang dilihat oleh mata, saraf penglihatan, daerah-daerah otak yang berhubungan (yang bersangkutan) (Pradopo, 2002: 80). Gambaran-gambaran angan yang bermacam-macam itu tidak dipergunakan secara terpisah-pisah oleh penyair dalam puisinya, tetapi dipergunakan bersamasama saling memperkuat dan saling menambah kepuitisannya.

Zaidan dalam Kamus Istilah Sastra (1991: 65) menjelaskan bahwa:

Citraan adalah daya bayang yang dihasilkan dari pengolahan kata-kata secara sungguh-sungguh untuk memberikan kesan indah di dalam suatu puisi; Suatu penggambaran pengalaman yang berkaitan dengan benda, peristiwa, dan keadaan yang di alami penyair dengan memakai kata-kata yang bersifat khas agar dapat memberikan gambaran secara lebih nyata, baik hal-hal yang bersifat kebendaan, metaforik, ataupun kejiwaan.

Pengimajian itu merupakan kata atau susunan kata-kata yang dapat mengungkapkan pengalaman sensori, misalnya penglihatan, pendengaran, dan perasaan. Pengimajian membuat baris maupun baris puisi seolah-olah mengandung gema suara atau disebut juga imaji auditif, benda yang tampak atau disebut imaji visual, sesuatu yang dapat kita rasakan, kita raba atau kita sentuh disebut imaji taktil.

Dari uraian diatas dapat disimpulkan bahwa pencitraan adalah susunan kata-kata yang mengungkapkan pengalaman sensoris dan menyebabkan makna-makna abstrak menjadi konkrit.

Mempelajari sastra itu ibarat memasuki hutan, makin ke dalam makin lebat, makin belantara. Dan itu terungkap bahwa karya sastra adalah fenomena kemanusiaan yang kompleks dan dalam (Culler, 1977: 8), salah satu contoh karya sastra itu adalah Puisi. Kita harus menganggap bahwa puisi itu suatu pekerjaan yang serius dan butuh keahlian tentunya bermanfaat, bukan hanya pekerjaan iseng. (Wellek, 1993: 26). Pradopo mengatakan puisi sebagai salah satu karya seni dapat dikaji dari bermacam macam aspeknya. Puisi dapat dikaji struktur dan unsur unsurnya, mengingat bahwa puisi itu adalah struktur yang tersusun dari bermacam macam unsur dan sarana kepuitisan.

Rifaterre (1978: 7) menegaskan bahwa puisi itu karangan yang terikat oleh: (1) banyak baris dalam tiap bait (kupret/strofa, suku karangan); (2) banyak kata dalam tiap baris; (3) banyak suku kata dalam tiap baris; (4) rima; dan (5) irama. Tentunya ada perbedaan dalam mendefinisikan puisi pendapat Abrams (1979: 18) menyatakan bahwa bila unsur unsur dari pendapat pendapat itu dipadukan, maka akan didapati garis garis besar tentang pengertian puisi yang sebenarnya. Unsur unsur tersebut berupa: emosi, imajinasi, pemikiran, ide, nada, irama, kesan pancaindera, susunan kata, kata kata kiasan, kepadatan, dan perasaan yang bercampur baur. Jadi puisi itu mengekspresikan pemikiran yang membangkitkan perasaan, yang merangsang imajinasi panca indera dalam susunan yang berirama.

\section{Metodedan Teknik}

Metode yang digunakan adalah metode deskriptif dengan ancangan sosiologi sastra. Teknik pengumpulan data dilakukan dengan menggunakan studi pustaka dari hasil penelitian yang sudah ada. Apa yang diamati dalam konteks kertas kerja ini terletak pada dua objek. Mengamati dan menghayati isi yang dipaparkan di dalam karya sastra daerah Sulawesi Selatan mengenai citraan di dalam puisi tersebut. Karya sastra hampir selalu mencerminkan jiwa pengarangnya di samping menggambarkan masyarakat yang disajikannya.

Pengumpulan data penelitian ini dilakukan melalui teknik perekaman melalui penutur sastra daerah Makassar, Mandar Bugis, dan Toraja. Teknik wawancara digunakan untuk mewawancarai penutur dan orang-orang yang dianggap memiliki informasi tentang puisi daerah tersebut.Data dalam penelitian ini diolah melalui kegiatan pengarsipan dengan cara mentranskripsikan puisi daerah dalam bentuk asli 
berbahasa Bugis, Makassar, Mandar, dan Toraja. Kemudian, mengalihbahasakannya ke dalam bahasa Indonesia. Setelah itu, menganalisis maknanya. Langkah selanjutnya, melakukan penganalisisan bentuk dan isinya. Terakhir, baru mengklasifikasi unsur-unsur citra berdasarkan bentuk dan isi.

Dalam penelitian ini data berasal dari bahasa lisan dan bahasa tulis. Data lisan diambil melalui penelitian lapangan yaitu bahasa informan di lokasi penelitian. Data bahasa tulis dikumpulkan melalui hasil-hasil penelitian yang sudah dilakukan atau buku-buku yang sudah diterbitkan yang relevan dengan masalah yang diteliti.

\section{Pembahasan}

Banyak orang terharu, terenyuh, atau terpukau ketika menikmati seuntai syair atau puisi. Segiapakah yang menyebabkan puisi menarik perhatian orang? Berdasarkan penafsiran subjektif, jawaban pertanyaan itu dapat beraneka ragam. Persoalan yang dikemukakan atau bentuk penyajian dapat menjadi penyebab keindahan puisi. Namun, pada dasarnya isi dan bentuk atau tema dan struktur secara bersama-sama menjalin keindahan puisi. Kedua aspek itu merupakan kesatuan yang utuh yang saling mendukung. Keserasian antara bunyi yang merdu, imajinasi yang dibangun, pemikiran yang dituangkan, watak yang dimunculkan, dan majas khas yang digunakan merupakan ramuan keapikan puisi.

Meskipun puisi dibentuk oleh banyak unsur, dalam kenyataannya sering hanya satu atau beberapa unsur yang menonjol. Keindahan unsur yang mencuat itulah yang acapkali dijadikan jawaban atas pertanyaan mengenai hal itu. Pesona puisi itu dapat terjadi karena, misalnya, citraan yang dominan.

Istilah citraan dalam puisi dapat sering dipahami dalam dua cara. Yang pertama, dipahami secara reseptif dari sisi pembaca. Dalam hal ini citraan merupakan pengalaman indera yang terbentuk dalam rongga imajinasi pembaca, yang ditimbulkan oleh sebuah kata atau rangkaian kata. Yang kedua, dipahami secara ekspresif, dari sisi penyair, yakni ketika citraan merupakan bentuk bahasa (kata atau rangkaian kata) yang dipergunakan oleh penyair untuk membangun komunikasi estetik atau untuk menyampaikan pengalaman inderanya. Hal ini senada dengan Segers (1978: 43) yang secara jelas mengatakan bahwa penggunaan kata yang konkret dan khas dan penataan kata-kata itu dalam larik dan bait sedemikian rupa sehingga menggugah timbulnya imaji disebut pengimajian atau pencitraan.

Ada beberapa jenis citraan yang dapat ditimbulkan puisi, yakni sebagai berikut.

\section{1) Citraan Penglihatan dalam puisi}

Citraan penglihatan ditimbulkan oleh indra penglihatan (mata). Citraan ini merupakan jenis yang paling sering digunakan penyair. Citraan penglihatan mampu memberi rangsangan kepada indra penglihatan sehingga hal-hal yang tidak terlihat menjadi seolah-olah terlihat.

(a) Bugis

\section{Siduppa matana caqberuna}

Ia na napobua

sitaro sengerennge

Sisengeq rimula wenni

Sibali sengeq topa rigiling tinrona

(Sikki, dkk.: 24)

Terjemahan:

Bila bertemu pandang maka

ia tersenyum

Hasilnya saling memeram kasih

Saling berkasihan

di awal malam

Sampai ke bilik tidurnya

(b) Makassar

Sirik paccea ri katte

Punna rapang belo-belo

Sikamma cinik

Sikamma mammuji

ngaseng (Nappu, 144)

Terjemahan:

Sirik dan pacce milik kita

Ibarat dekorasi

Yang memandang

Pasti terpesona 
(c) Mandar

Ia iannamo lopi

Sundallaq lanterana

Iqdami tuqu

Natanduq kappal api

(Sikki, dkk.: 108)

Terjemahan:

Yang mana saja perahu

Yang menyala terang lenteranya

Tidaklah ia

Ditabrak kapal api

(d) Toraja

Moina bulan kitiro

Moi anna bentoen

Tae padanna

Kematanta sitiro

(Jemmain, hlm: 16)

Terjemahan:

Biar kami memandang bulan

Biar memandang bintang

Takkan serupa

Bila kita bertemu pandang

Pada kutipan diatas jelas terlihat adanya citra penglihatan, adanya kata siduppa matana 'bertemu pandang', sikamma cinik 'yang memandang', sundallaq 'yang menyala terang', moina 'memandang' semakin memperkuat kesan dan maknapuisidalam bahasa bahasa kias lainnya.

\section{2) Citraan Pendengaran dalam Puisi}

Citraan pendengaran berhubungan dengan kesan dan gambaran yang diperoleh melalui indra pendengaran (telinga). Citraan ini dapat dihasilkan dengan menyebutkan atau menguraikan bunyi suara, misalnya dengan munculnya diksi sunyi, tembang, dendang, suara mengiang, berdentum-dentum, dan sayup-sayup.

(a) Bugis

\section{Maladenni ronnang wenni e}

Baja maegatona

Lalo tenripaseng

(Sabriah, 1997: 140)
Terjemahan:

Sudah larut malam

Angin sudah banyak juga

Lewat tanpa pesan

(b) Makassar

Takunjungak bangung turuk

Nakuguncirik gulingku

Kualleanna

Tallanga natoalia

Terjemahan:

Takkan kuturutkan alunan arus

Kemudi terlah kupasang

Aku lebih sudi tenggelam

Daripada surut kembali

(c) Mandar

ummarraq sida sangiq

aqdappangammaq todiq

iqdai ulle

sessa tammallawangang

Terjemahan:

meraung merintih

bersama tangis

beri ampunlah aku

aku tak mampu

disiksa tak henti-hentinya

(d) Toraja

Kenna tang oni totosik

Kulu-kuluna panggalaq

Kamimi dikkaqna kami

Mate tang ditangiqi

(Jemmain, hlm.: 11)

Terjemahan:

Andai bukan bunyi

burung hantu

Unggas-unggas rumba

Kasihanilah kami ini

Mati tak ditangisi

Citraan pendengaran yang terdapat dalam beberapa kata yang melengkapi kalimat puisi di atas, yakni,baja maegatona, lalo tenripaseng 'angin sudah banyak juga, lewat tanpa pesan', takunjungak 
bangung turuk 'takkan kuturutkan alunan arus', ummarraq sida sangiq'meraung merintih bersama tangis', dan kenna tang oni totosik 'andai bukan bunyi burung hantu'. Wujud citraan di atas divisualisasikan dengan jelas oleh penyair pada aktivitas yang bisa di dengar oleh pancaindera

\section{3) Citraan Penciuman dalam puisi}

Citraan penciuman atau pembauan disebut juga citraan olfactory. Dengan membaca atau mendengar kata-kata tertentu, kita seperti mencium bau sesuatu. Citraan atau pengimajian melalui indra penciuman ini akan memperkuat kesan dan makna sebuah puisi.

(a) Bugis

Mangidengi camanike

Tebbu surekna tappangeng

Panreng pole polipu

Manyamenniro

nyawana (Sabriah, 1997: 224)

Terjemahan:

Anak mungil Sagala itu

Mengidamkan sesuatu

Nenas dari palipu

Sudah tenang perasaannya

(b) Makassar

Puangi bunga ejaya

Makatutui rasanna

Manna mabauk

Teai mabauk dudu

(Mathes, 1983: 425)

Terjemahan:

Sampaikan si kembang merah

Agar baunya dijaga

Walaupun harum

Jangan terlalu semerbak

(c) Mandar

Diang pandeng mane kambang

tuo di rappaq lembong

minang dipala

minangi namasarri
Terjemahan:

ada gadis beranjak dewasa

tumbuh pada buih gelombang

semakin dipakai

semakin harum

(d) Toraja

Tongan mintu tapau

Deen bunga inde banna

Bunga tonna leppang batik

Tanna saile olli

(Jemmain, hlm.: 8)

Terjemahan:

Betul yang kau katakan

Di rumah ini ada bunga

Bunga yang tak disinggahi

belalang

Tak dipandang ulat

Jika diamati dalam keempat kutipan puisi daerah di atas, tampak sekali betapa dalam penggambaran citra penciuman yang tertuang di dalamnya. Penggambaran itu memang sangat abstrak, tetapi di balik keabstrakan itulah terdapat makna yang sangat dalam. Kata-kata itu adalah panreng pole polipu 'nenas dari palipu', teai mabauk dudu jangan terlalu semerbak', minangi namasarri'semakin harum' dan tongan mintu tapau, deen bunga inde banna betul yang kau katakan, dirumah ini ada bunga.

\section{4) Citraan Pencicipan atau Pencecapan dalam Puisi}

Citraan pencicipan disebut juga citraan gustatory, yakni citraan yang muncul dari puisi sehingga kita seakan-akan mencicipi suatu benda yang menimbulkan rasa asin, pahit, asam, manis, ataupedas.

(a) Bugis
Deknaro peddi padanna
Purani sipakkalu
Magi namassala
(Sabriah, 1997: 237) 
Terjemahan:

Sungguh pedih rasanya

Sudah pernah seia sekata

Tiba-tiba berpisah

(b) Makassar

Kuntungku laklasak tembang

Jappok lure sikaranjeng

Kupattunrangi

Lesseka sigigi jangka

(Basang, 1988: 90)

Terjemahan:

Biar aku hancur bagai

ikan tembang

Busuk seperti ikan teri

Aku bersumpah

Tak akan mundur segigi sisir

(c) Mandar

Nagilingangmaq gajangna

Nasangaq na matindong

Kopi loppaqu

Meqakkeq di bojaqu

Terjemahan:

Digeserkannya kepadaku kerisnya

Disangkanya aku akan lari

Kopi panasku

Ketika aku berangkat

dari rumah

(d) Toraja

Diona tetukna rinding

Ri tanggana manangnga

Natidukunni

Penawa golla-golla

(Jemmain, hlm.: 15)

Terjemahan:

Aku di sudut dinding

Di tengah-tengah pemele

Tempat berkumpul

Hati dan budi yang manis

Dalam analisis citraan ini dijumpai adanya kata maupun kalimat yang mengandung unsur citraan pengecap atau rasa, yaitu deknaro peddi padanna 'sungguh pedih rasanya', jappok lure sikaranjeng 'busuk seperti ikan teri', kopi loppaqu kopipanasku' dan penawa golla-golla 'hati dan budi yang manis'.

\section{5) Citraan Gerak dalam puisi}

Dalam larik-larik puisi, kamu pun dapat menemukan citraan gerak atau kinestetik. Yang dimaksud citraan gerak adalah gerak tubuh atau otot yang menyebabkan kita merasakan atau melihat gerakan tersebut. Munculnya citraan gerak membuat gambaran puisi menjadi lebih dinamis.

(a) Bugis

Cokkong lebu bulu ammo

Ajak mutakkalupa

Pole ri ammekku

(Sabriah, 1997: 248)

Terjemahan:

Jika engkau sampai di pucuk

Jangan hendaknya engkau lupa

Engkau berasal dari bawah

(b) Makassar

Nampako maccuklak lebong

Nakurompong-rompong

memang Lompoko naik

Kutambai pakrompongku

(Hakim, 1998: 56)

Terjemahan:

Sejak dinda tumbuh seperti tebu

Dinda telah kupagar

Semoga dinda cepat besar

Pagarku kuperkuat

(c) Mandar

Muaq diang na maqala

Pandeng pura utujuq

Apa gunana

Pataeng di seqdeu

Terjemahan:

Bila ada yang akan mengambil

Pandan yang sudah kuikat

Apakah gunanya

Senjata tajam di pinggangku 
(d) Toraja

Mattumbai na taeqna rapeq

Sokko soloq bombongna

Marundun bongi

Musanlaq cappana

(Jemmain, hlm.: 16)

Terjemahan:

Bagaimana tak terkulai

Menuju ke bawah puncaknya

Setiap malam

Kau sapu puncaknya

Pada kutipan puisi-puisi diatas citraan gerak dapat terlihat pada kata cokkong lebu bulu ammo 'jika engkau sampai di pucuk', nampako maccuklak lebong 'sejak dinda tumbuh seperti tebu', muaq diang na maqala, pandeng pura utujuq 'bila ada yang akan mengambil, pandan yang sudah kuikat', dan musanlaq cappana 'kau sapu puncaknya'.

\section{Penutup}

Citraan (gambaran angan-angan) adalah gambarangambaran dalam pemikiran dan bahasa yang menggambarkannya. Gambaran pemikiran ini adalah sebuah efek dalam pemikiran yang sangat menyerupai gambaran yang dihasilkan oleh pengungkapan kita terhadap sebuah objek yang dilihat oleh mata, saraf penglihatan, daerah-daerah otak yang berhubungan (yang bersangkutan). Pencitraan sama dengan pengimajian, imaji dan citraan. Pencitraan atau citraan sangat bermanfaat dalam menghidupkan puisi.

Setelah membaca dan memahami serta menganilisis pencitraan yang terdapat pada kutipan-kutipan puisi daerah Sulawesi Selatan dapat disimpulkan bahwa puisi tersebut mengandung unsur citraan, yakni:

1. setiap puisi daerah Sulawesi Selatan mampu dianalisis sesuai dengan unsur citraan, yakni penglihatan, pendengaran, rabaan, pengecap dan gerak;

2. puisi-puisi daerah Sulawesi Selatan memiliki unsur citraan penglihatan, pendengaran, rabaan, pengecap dan gerak; dan
3. citraan yang terrefleksi dalam puisi-puisi daerah Sulawesi Selatan, ada kalanya ditemukan beberapa unsur dalam satu bait.

Dari cerminan tersebut di atas, untuk mengetahui seberapa banyak sastra tulis khususnya puisi yang bisa memberikan nilai-nilai lebih (citraan) yang mampu membuat perubahan ke arah yang lebih baik. Pembaca harus bisa memilah dan memilih karya sastra yang apresiatif positif. Pembaca mesti pandai mengungkap dan mempelajari nilai estetisnya, bukan hanya hiburan semata. Untuk mengetahuinya perlu diadakan penelitian-penelitian terhadap kesusastraan kita, sehingga sastra tulis tidak hanya hiburan semata, tetapi juga dapat dibaca dipahami dan dijadikan media pembelajaran yang positifoleh masyarakat luas.

Mempelajari dan mengembangkan puisi puisi sastra sangat perlu ditingkatkan Oleh karena itu kita sebagai pemerhati bahasa dan sastra daerah mempunyai tugas untuk menelusurinya dan terus mensosialisasikannya, sehingga dapat memperbanyak wawasan kesusastraan Indonesia.

\section{Daftar Pustaka}

Abrams, M.H. 1979. The Mirror and The Lamp. London-New York: Oxford University Press.

Basang, Djirong. 1986. Taman sastra Makassar. Ujung Pandang: Percetakan Ofset CV Alam.

Culler, Jonathan. 1977. Structuralist Poetics. London: Roudledge \& Kegan Paul.

Damono, Supardi Djoko,1990. Kesusastraan Indonesia Modern. Jakarta: PT Gramedia.

Ermaida. 1999. Panngajarak Tu Panitra dalam Sastra Makassar. Jakarta: Pusat Pembinaan dan Pengembangan Bahasa. Departemen Pendidikan dan Kebudayaan.

Hakim, Zainuddin. 1998. "Kelong dan Fungsinya dalam Masyarakat". Bunga Rampai Hasil Penelitian Bahasa dan Sastra. Ujung Pandang: Balai Penelitian Bahasa.

Howard, J. Roy. 2001. Hermeneutika, Wacana Analitis, Psikososial, dan Ontologuis. Bandung: Nuansa Cendekia. 
Jemmain. 1999. Syair-Syair dalam Sastra Toraja. Jakarta: Pusat Pembinaan dan Pengembangan Bahasa. Departemen Pendidikan dan Kebudayaan.

Nappu, Sahabuddin. 1986. Kelong dalam Sastra

Makassar. Jakarta: Proyek Penerbitan Buku Sastra Indonesia dan Daerah.

Pradopo, Rachmat Djoko.1994. Prinsip-Prinsip

Kritik Sastra. Jogyakarta : Gajah Mada UniversityPress. 1995.Beberapa teori sastra, Metode

Kritik dan Penerapannya. Yogyakarta: Pustaka Pelajar. 2002.Pengkajian Puisi. Yogyakarta: Gadjah Mada University Press.

Rifaterre, Michael. 1978. Semiotics of Poetry. Bloomington \& London: Indiana University Press.

Saad Saleh. 1967. "Catatan Kecil Sekitar Penelitian Kesusastraan”. Dalam Lukman Ali (ed.) Bahasa dan Kesusastraan Indonesia Modern sebagai Cermin Manusia Modern. Jakarta: Gunung Agung.
Sabriah, 1997. 'Nilai Religi dalam Elong Ugi". Bunga Rampai Hasil Penelitian Bahasa dan Sastra. Ujung Pandang: Balai Penelitian Bahasa.

Segers, Rien T. 1978. The Evaluation of Literary Texts. The Peter de Ridder Press: Lisse.

Sikki, Muhammad. dkk. 1991. Nilai-Nilai Budaya dalam Susastra Daerah Sulawesi Selatan. Jakarta: Pusat Pembinaan dan Pengembangan Bahasa. Depdikbud.

Stanton, Robert. 1965. An Introduction to Fiction. London: Hold, Rinehart and Winston, Inc.

Teeuw, A. 1983. Membaca dan Menilai Sastra. Jakarta: Gramedia.

Wellek, Rene. Agustin Warren. 1993.Teori Kesusastraan. Jakarta: PT Gramedia.

Zaidan, Abdul Rozak. 1991. Kamus Istilah Sastra. Jakarta: Departemen Pendidikan dan Kebudayaan. 
